\title{
Effects of FTO and PPAR $\gamma$ variants on intrauterine growth restriction in a Brazilian birth cohort
}

\author{
M.R. Barbieri ${ }^{1 \oplus \bowtie}$, A.M. Fontes $^{2 \oplus}$, M.A. Barbieri ${ }^{1 \oplus}$, M.C.P. Saraiva ${ }^{3 \oplus}$, V.M.F. Simões ${ }^{4 \oplus}$ \\ A.A.M. da Silva ${ }^{4 \oplus}$, K.J. Abraham ${ }^{5}$, and H. Bettiol ${ }^{10}$ \\ ${ }^{1}$ Departamento de Puericultura e Pediatria, Faculdade de Medicina de Ribeirão Preto, Universidade de São Paulo, \\ Ribeirão Preto, SP, Brasil \\ ${ }^{2}$ Departamento de Genética, Faculdade de Medicina de Ribeirão Preto, Universidade de São Paulo, Ribeirão Preto, SP, Brasil \\ ${ }^{3}$ Departamento de Clínica Infantil, Faculdade de Odontologia de Ribeirão Preto, Universidade de São Paulo, \\ Ribeirão Preto, SP, Brasil \\ ${ }^{4}$ Departamento de Saúde Pública, Centro de Ciências da Saúde, Universidade Federal do Maranhão, São Luís, MA, Brasil \\ ${ }^{5}$ Departamento de Economia, Faculdade de Economia, Administração e Contabilidade de Ribeirão Preto, Universidade de \\ São Paulo, Ribeirão Preto, SP, Brasil
}

\begin{abstract}
Intrauterine growth restriction (IUGR) is related to a higher risk of neonatal mortality, minor cognitive deficit, metabolic syndrome, and cardiovascular disease in adulthood. In previous studies, genetic variants in the FTO (fat mass and obesityassociated) and PPAR (peroxisome proliferator-activated receptor-gamma) genes have been associated with metabolic disease, body mass index, and obesity among other outcomes. We studied the association of selected FTO (rs1421085, rs55682395, rs17817449, rs8043757, rs9926289, and rs9939609) and PPAR (rs10865710, rs17036263, rs35206526, rs1801282, rs28763894, rs41516544, rs62243567, rs3856806, and rs1805151) single-nucleotide polymorphisms (SNPs) with IUGR, through a case-control study in a cohort of live births that occurred from June 1978 to May 1979 in a Brazilian city. We selected 280 IUGR cases and 256 controls for analysis. Logistic regression was used to jointly analyze the SNPs as well as factors such as maternal smoking, age, and schooling. We found that the PPAR $\gamma$ rs 41516544 increased the risk of IUGR for male offspring (OR 27.83, 95\% $\mathrm{Cl} 3.65-212.32)$ as well as for female offspring (OR=8.94, 95\% Cl: 1.96-40.88). The FTO rs9939609 TA genotype resulted in a reduced susceptibility to IUGR for male offspring only (OR=0.47, 95\% Cl: $0.26-0.86)$. In conclusion, we demonstrated that PPAR $\gamma$ SNP had a positive effect and FTO SNP had a negative effect on IUGR occurrence, and these effects were gender-specific.
\end{abstract}

Key words: IUGR; FTO; PPAR ; SNPs; Cohort study

\section{Introduction}

Intrauterine growth restriction (IUGR) is known to be related to a higher risk of neonatal mortality, minor cognitive deficits, school problems, metabolic syndrome (MetS), and cardiovascular disease in adulthood (1-4).

Although the consequences of IUGR have been widely reported, causal explanations are still unclear. In addition to suggestions about the importance of maternal, fetal, placental, and genetic factors or any combination thereof $(5,6)$, other hypotheses have been proposed, among them: 1) the Barker hypothesis, which suggests that the maternal uterine environment in pregnancy has long-term effects in adulthood resulting in increased metabolic disease and diabetes risk $(1,7) ; 2)$ the fetal insulin hypothesis, which proposes that the insulin secreted by the fetal pancreas in response to the maternal glucose concentration affects both newborn size and predisposition to adult diseases (8); and 3 ) the genetic factors hypothesis, which is supported by the observation that IUGR tends to cluster in families and recur in successive pregnancies $(9,10)$. In this regard, a number of singlenucleotide polymorphisms (SNPs) in genes involved in the efficiency of the metabolism of specific macronutrients may have a relevant role for adult MetS in different populations (11-13).

Several SNPs of the human FTO gene (fat mass and obesity-associated, NM_001080432) have been associated with body mass index (BMI) $(13,14)$ and susceptibility to type 2 diabetes mellitus (T2DM) and obesity $(15,16)$. In the same way, several allelic variants of the PPARy gene (peroxisome proliferator-activated receptor-gamma) have 
been associated with MetS and T2DM (17-20). A metaanalysis suggests that FTO may represent a low-penetrance susceptible gene for obesity that may vary according to ethnic composition of the population (21). Considering that IUGR is associated with MetS in adulthood and allele variants of the FTO and PPAR $\gamma$ genes are associated with obesity and MetS later in life, it is plausible to hypothesize that these allele variants may also have a role in intrauterine growth, with potential effects on obesity and metabolic disorders later in life.

Few studies have investigated the possible effect of FTO and PPAR $\gamma$ SNPs on fetal growth and the results are controversial. The rs9939609 A:A FTO genotype was associated with faster biparietal diameter and head circumference growth velocities between 11 and 34 weeks of gestation than the T:T FTO genotype (22). The FTO rs9939609 A:A genotype has an influence on fetal growth restriction after 28 weeks of gestation (22). The FTO gene has also been studied in relation to the small for gestational age (SGA) condition (13), which is closely related to IUGR (23). Although there are studies that were unable to find association between fetal growth and PPAR $\gamma$ SNPs (24), others have shown a reduced expression of $P P A R \gamma$ in placentas of SGA children, maybe related to higher DNA methylation (25), which is more prone to arise after the first trimester of gestation (26). However, if methylation is a cause or a consequence of SGA is still unknown.

Thus, in view of these controversies, this paper examines the frequency of selected FTO and PPAR SNPS with regard to their association with IUGR in a Brazilian cohort, while taking into account additional confounding factors also potentially related to IUGR.

\section{Material and Methods}

\section{Subjects}

This was an unmatched case-control study nested in a prospective cohort study started in 1978/79 in Ribeirão Preto, involving children born in hospitals to mothers residing in the municipality (23). The birth cohort consists of a total of 9067 children born in eight medical facilities in Ribeirão Preto from June 1978 to May 1979, corresponding to $98 \%$ of live infants. Only $3.5 \%$ of the infants were excluded due to refusal to participate or early discharge. After the exclusion of children whose families did not reside in the municipality (2094) and of twins (146), 6827 individuals of the initial sample were available for the study.

The sample size was calculated considering a $95 \%$ confidence level, a power of $80 \%$, and an odds ratio of 2.1 estimated a priori. Considering a frequency of $43 \%$ for the rs9939609 A allele (14) and a ratio of one control to each case, the minimum number of participants in the analysis was calculated in 232, i.e., 116 cases and 116 controls. Cases and controls for the present study were selected from participants in the follow-up of 2002/3 ( $n=2063)$ when blood samples were obtained. All individuals defined as having IUGR at birth were included as cases $(n=280)$. IUGR was defined by the birth weight ratio (BWR), calculated by the ratio between the child's weight and the median weight for gestational age according to the William's curve (27), and growth restriction was defined by a BWR $\leqslant 0.85$. An additional 276 non-IUGR children from the follow-up were selected at random. Blood samples of all 556 participants were available and were used for genotyping.

The participants were stratified according to gender, as females are more likely to develop IUGR (28), with 253 being males (45.7\%) and 303 being females (54.3\%). The statistical analysis was performed separately for each sex.

In order to study the effects of genotypes on IUGR, the confounding effects of the following covariates at birth were included: maternal education in years of schooling $(<9$ and $\geqslant 9$ ), maternal smoking during pregnancy (yes, if smoked at least one cigarette per day), and maternal age $(<20,20$ to $34, \geqslant 35$ years). The study was reviewed and approved by the Research Ethics Committee of the Ribeirão Preto Medical School, University of São Paulo (Process No. 7609/99), and a biological bank of all blood samples was approved later (Process No. 10761/2008).

\section{Polymerase chain reaction}

Genomic DNA was obtained from $40 \mathrm{~mL}$ of a peripheral blood sample collected from each participant. The DNA extraction was performed using the FlexiGene DNA (250) Kit (Qiagen, USA), according to the manufacturer's recommendations. The extracted genomic DNAs were quantified using NanoDrop equipment (ThermoScientific, USA), according to the manufacturer's instructions.

SNP analysis was performed by HRM (high-resolution melting) technique. First, the regions of interest of the FTO and PPAR $\gamma$ genes were amplified by PCR (polymerase chain reaction). To identify the FTO SNPS, the following primer pairs were used: 1) forward 5'-CCATGAGCCAG ATTTTCCAT-3' and reverse 5'-TGGAGGTCAGCACAG AGG-3' (rs1421085 and rs55682395); 2) forward 5'-CG GTGAAGAGGAGGAGATTG-3' and reverse $5^{\prime}$-CCCAGT TTCTCCAAGGAAGC-3' (rs17817449 and rs8043757); and 3) forward 5'-AACTGGCTCTTGAATGAAATAGG-3' and reverse 5'-TGCTCTCCCACTCCATTTCT-3' (rs9926289 and rs9939609). To identify the PPAR $\gamma$ SNPs, the following primer pairs were used: 1) forward 5'-TCATGTAGGTAA GACTGTGTAG-3' and reverse 5'-AACCAGAGAGCAGAT CATC-3' (rs10865710 and rs17036263); 2) forward 5'-AA CGGATTGATCTTTTGCTAG-3' and reverse 5'-TGGAA GACAAACTACAAGAGC-3' (rs35206526 and rs1801282); and 3) forward 5'-AGGTTTGCTGAATGTGAAG-3' and reverse 5'-GGAAGAAGGGAAATGTTGG-3' (rs28763894, rs41516544, rs62243567, rs3856806, and rs1805151). The equipment used for amplification of the corresponding 
fragments was the Gene Amp PCR System 9700 (Applied Biosystems, USA).

Then, SNPs analysis by HRM on the DNA samples of the selected individuals was performed on the ViiA7 Real Time PCR System (ThermoFisher Scientific), according to the manufacturer's instructions.

\section{DNA sequencing}

Sequencing of samples to confirm the presence or absence of SNPs in the candidate genes was performed using the ABI Prism Big Dye Terminator Cycle Sequencing kit (Applied Biosystems), according to the manufacturer's instructions. Then, the samples were electrophoresed on the ABI Prism 3130 automated sequencer (Applied Biosystems). Some samples were used as control variants after PCR, but during the analysis by HRM some samples that differed from the control variants were also sequenced to identify and confirm the SNPs.

\section{Statistical analysis}

First, for quality control, all polymorphisms were tested for Hardy-Weinberg equilibrium (HWE) using the HardyWeinberg Library in the $\mathrm{R}$ programming language. The criterion used to discard a given polymorphism was based on a violation of HWE with a P-value less than 0.001 using only the controls (29). With this criterion, all polymorphisms with fixed genotypes were automatically excluded.

In order to decide which covariates to include in the adjusted analysis, we treated IUGR as a categorical factor and computed the unadjusted P-values between IUGR and other risk factors. For each risk factor, a chi-squared test was performed to assess the strength of association with growth restriction.

For each gender group, the association of the SNPS and IUGR was assessed by multivariate logistic regression separately. The partial odds ratio (OR) for each covariate was calculated and $95 \%$ confidence intervals for all ORs were obtained. Statistical significance was based on a $5 \%$ threshold. All genotypes were treated without reference to a specific genetic model such as dominance of one allele or an additive model. In the final statistical analysis, only individuals with no missing covariates were retained.

\section{Results}

Among the 556 participants, we determined the genotype frequencies of 14 SNPs and one indel; six of them were in the FTO gene and eight of them and one indel in the PPAR $\gamma$ gene. A complete description of the polymorphisms in the FTO and PPAR $\gamma$ genes is shown in Table 1. Our results showed that five of the markers were not polymorphic in this population. As seen, one SNP in the FTO gene (rs55682395), three SNPs and one indel in the PPAR gene (rs28763894, rs62243567, rs1805151, and rs35206526) were fixed and showed no variation across different individuals.
The genotype and allele frequencies for the ten polymorphic markers from the FTO and PPAR $\gamma$ genes separated by IUGR and non-IUGR groups are listed in Table 2. Higher differences in genotype and allele distributions between IUGR and non-IUGR groups were observed for the heterozygous genotypes $A G$ and CT of $P P A R \gamma$ SNPs, rs41516544 and rs3856806. For the FTO gene, three markers were in HWE (rs1421085, rs9926289, and rs9939609), and for the PPAR $\gamma$ gene, there were four SNPs (rs17036263, rs1801282, rs41516544, and rs3856806).

To decide which SNP to retain, we checked the unadjusted statistical significance of association with IUGR for each SNP separately among males and females (Table 3). Among FTO SNPs, we found that both rs9939609 and rs9926289 among males and females had the strongest $(P$-value $=0.059)$ association with IUGR. Thus, for the analyses of effects of the FTO SNPs on IUGR we used only rs9939609, which has also been discussed (13). Among the PPAR $\gamma$ SNPs, a high degree of collinearity was also observed between certain SNPs. For example, the Fisher exact test for association between the markers rs3856806 and rs41516544 for both males and females was highly significant ( $P$-values $<2.2 \times 10^{-16}$ and $1.102 \times 10^{-12}$, respectively). Using the same reasoning for choosing an SNP, the only PPAR $\gamma$ SNP with a $P$-value less than 0.001 was rs41516544 and therefore, retained in the study for further analyses.

Table 3 shows the frequency of known IUGR predictors and the selected SNPs as well as their unadjusted associations with IUGR stratified by sex. In this study, the proportion of maternal smoking was higher in IUGR than in non-IUGR participants independent of sex. We also observed that mothers older than 35 years showed a lower rate of IUGR only among female offspring. The rs 41516544 SNP from the PPAR $\gamma$ gene appears to be a significant risk factor for IUGR independent of sex, while the rs9939609 SNP of the FTO gene may have a significant impact on IUGR only for male offspring.

All the variables in Table 3 were included in a multivariate logistic regression to assess their joint effect on IUGR. The three genotypes in the rs9939609 SNP were treated without reference to a specific genetic model such as dominance of one allele or an additive model. For rs41516544, there were only two genotypes present, so the choice of model was less of an issue. All the adjusted ORs along with the 95\% confidence intervals are presented in Table 4. As earlier, the results are separated by sex. For both sexes, only individuals with no missing values were retained in the analysis.

We observed that for male offspring the heterozygous AG genotype in the rs41516544 SNP of the PPAR $\gamma$ gene was associated with a 28-fold increase in the risk for IUGR, compared with the AA homozygote, while for females there was a 9-fold increase in risk. In male offspring, the heterozygous TA genotype in the rs9939609 
Table 1. Genotype frequencies and classification of single-nucleotide polymorphisms (SNPs) of the FTO (fat mass and obesity-associated) and PPAR (peroxisome proliferator-activated receptor-gamma) genes.

\begin{tabular}{|c|c|c|c|}
\hline Polymorphisms (GRCH38.p12) & Genotype & Participants $(n=556) n(\%)$ & Classification \\
\hline \multicolumn{4}{|l|}{ FTO } \\
\hline rs $1421085 \mathrm{~T}>\mathrm{C}$ & $T / T$ & $229(41.2)$ & Intron variant \\
\hline \multirow[t]{2}{*}{ chr16: 53767042} & $\mathrm{~T} / \mathrm{C}$ & $253(45.5)$ & \\
\hline & $\mathrm{C} / \mathrm{C}$ & $74(13.3)$ & \\
\hline rs55682395 C > T & $\mathrm{C} / \mathrm{C}$ & $556(100)$ & Intron variant \\
\hline \multirow[t]{2}{*}{ chr16: 53767031} & $\mathrm{C} / \mathrm{T}$ & $0(0.0)$ & \\
\hline & $T / T$ & $0(0.0)$ & \\
\hline rs17817449 T>G & $T / T$ & $287(51.6)$ & Intron variant \\
\hline \multirow[t]{2}{*}{ chr16: 53779455} & $T / G$ & $269(48.4)$ & \\
\hline & G/G & $0(0.0)$ & \\
\hline rs8043757 A > T & $\mathrm{A} / \mathrm{A}$ & $277(49.8)$ & Intron variant \\
\hline \multirow[t]{2}{*}{ chr16: 53779538} & $\mathrm{~A} / \mathrm{T}$ & $269(48.4)$ & \\
\hline & $T / T$ & $10(1.8)$ & \\
\hline rs9926289 G > A & G/G & $205(36.9)$ & Intron variant \\
\hline \multirow[t]{2}{*}{ chr16: 53786591} & $\mathrm{G} / \mathrm{A}$ & $247(44.4)$ & \\
\hline & $\mathrm{A} / \mathrm{A}$ & $104(18.7)$ & \\
\hline rs9939609 T>A & $T / T$ & 205 (36.9) & Intron variant \\
\hline \multirow[t]{2}{*}{ chr16: 53786615} & T/A & $247(44.4)$ & \\
\hline & $\mathrm{A} / \mathrm{A}$ & $104(18.7)$ & \\
\hline \multicolumn{4}{|l|}{ PPAR $\gamma$} \\
\hline rs $10865710 \mathrm{C}>\mathrm{G}$ & $\mathrm{C} / \mathrm{C}$ & $352(63.3)$ & Intron variant \\
\hline \multirow[t]{2}{*}{ chr 3: 12311699} & $\mathrm{C} / \mathrm{G}$ & $204(36.7)$ & \\
\hline & G/G & $0(0.0)$ & \\
\hline rs $17036263 \mathrm{~A}>\mathrm{G}$ & $\mathrm{A} / \mathrm{A}$ & $542(97.5)$ & Intron variant \\
\hline \multirow[t]{2}{*}{$\operatorname{chr} 3: 12311776$} & $\mathrm{~A} / \mathrm{G}$ & $14(2.5)$ & \\
\hline & G/G & $0(0.0)$ & \\
\hline rs35206526 TAGA >- & TAGA/TAGA & $556(100)$ & Intron variant indel \\
\hline $\operatorname{chr} 3: 12351542$ & TAGA/- & $0(0.0)$ & \\
\hline rs 1801282 C > G & $\mathrm{C} / \mathrm{C}$ & $479(86.2)$ & Missense variant \\
\hline \multirow[t]{2}{*}{ chr 3: 12351626} & $\mathrm{C} / \mathrm{G}$ & $77(13.8)$ & p.Pro12Ala \\
\hline & $\mathrm{G} / \mathrm{G}$ & $0(0.0)$ & \\
\hline rs28763894 A>G & $\mathrm{A} / \mathrm{A}$ & $556(100)$ & Synonymous variant \\
\hline \multirow[t]{2}{*}{ chr 3: 12433941} & $A / G$ & $0(0.0)$ & p. $G \ln 410=$ \\
\hline & G/G & $0(0.0)$ & \\
\hline rs41516544 A>G & $\mathrm{A} / \mathrm{A}$ & $516(92.8)$ & Synonymous variant \\
\hline \multirow[t]{2}{*}{ chr 3: 12433998} & $A / G$ & $40(7.2)$ & p.Ser $429=$ \\
\hline & $\mathrm{G} / \mathrm{G}$ & $0(0.0)$ & \\
\hline rs62243567 A $>C$ & $\mathrm{C} / \mathrm{C}$ & $556(100)$ & Missense variant \\
\hline \multirow[t]{2}{*}{ chr 3: 12434056} & $\mathrm{~A} / \mathrm{C}$ & $0(0.0)$ & p.His449Asn \\
\hline & $\mathrm{A} / \mathrm{A}$ & $0(0.0)$ & \\
\hline rs3856806 C > T & $\mathrm{C} / \mathrm{C}$ & $424(76.3)$ & Synonymous variant \\
\hline \multirow[t]{2}{*}{ chr 3: 12434058} & $\mathrm{C} / \mathrm{T}$ & $132(23.7)$ & p.His $449=$ \\
\hline & $T / T$ & $0(0.0)$ & \\
\hline rs $1805151 \mathrm{C}>\mathrm{T}$ & $\mathrm{C} / \mathrm{C}$ & $556(100)$ & Synonymous variant \\
\hline \multirow{2}{*}{ chr 3: 12434068} & $\mathrm{C} / \mathrm{T}$ & $0(0.0)$ & p.Leu $453=$ \\
\hline & $\mathrm{T} / \mathrm{T}$ & $0(0.0)$ & \\
\hline
\end{tabular}

SNP of the FTO gene appeared to be associated with a lower risk for IUGR compared with the TT genotype. In female offspring, no similar effect was observed. For female offspring, a maternal age of 35 years or more seemed to be associated with a lower risk for IUGR compared with maternal age of 20 to 34 years, which was considered the baseline category. This effect was not observed in male offspring. Finally, maternal smoking was a risk factor only in female offspring, while maternal education did not appear to be a risk factor for children of either sex. 
Table 2. Genotype and allele frequencies of the polymorphic single-nucleotide polymorphisms (SNPs) from FTO (fat mass and obesity-associated) and PPAR (peroxisome proliferator-activated receptor-gamma) genes in intrauterine growth restriction (IUGR) and control groups.

\begin{tabular}{|c|c|c|c|c|c|c|c|}
\hline \multirow[t]{2}{*}{ Polymorphisms } & \multicolumn{3}{|c|}{ Genotype frequency } & \multicolumn{3}{|c|}{ Allele frequency } & \multirow[t]{2}{*}{ HWE P-value } \\
\hline & Genotype & IUGR $(n=280) n(\%)$ & Non-IUGR $(n=276) n(\%)$ & Allele & IUGR $(n=280)$ & Non-IUGR $(n=276)$ & \\
\hline \multicolumn{8}{|l|}{ FTO } \\
\hline \multirow[t]{3}{*}{ rs1421085 T>C } & $\mathrm{T} / \mathrm{T}$ & $111(39.7)$ & $118(42.8)$ & $\mathrm{T}$ & 0.63 & 0.65 & 0.5875 \\
\hline & $\mathrm{T} / \mathrm{C}$ & $132(47.1)$ & $121(43.8)$ & C & 0.37 & 0.35 & \\
\hline & $\mathrm{C} / \mathrm{C}$ & $37(13.2)$ & $37(13.4)$ & & & & \\
\hline \multirow[t]{2}{*}{ rs $17817449 \mathrm{~T}>\mathrm{G}$} & $\mathrm{T} / \mathrm{T}$ & $134(47.9)$ & $153(55.4)$ & $\mathrm{T}$ & 0.74 & 0.78 & $<0.001$ \\
\hline & $T / G$ & $146(52.1)$ & $123(44.6)$ & G & 0.26 & 0.22 & \\
\hline \multirow[t]{3}{*}{ rs8043757 A $>$ T } & $\mathrm{A} / \mathrm{A}$ & $130(46.4)$ & $147(53.3)$ & $A$ & 0.72 & 0.76 & $<0.001$ \\
\hline & $\mathrm{A} / \mathrm{T}$ & $146(52.2)$ & $123(44.6)$ & $\mathrm{T}$ & 0.28 & 0.24 & \\
\hline & $\mathrm{T} / \mathrm{T}$ & $4(1.4)$ & $6(2.1)$ & & & & \\
\hline \multirow[t]{3}{*}{ rs9926289 G > A } & $\mathrm{G} / \mathrm{G}$ & $115(41.1)$ & $90(32.6)$ & G & 0.61 & 0.57 & 0.9003 \\
\hline & $\mathrm{G} / \mathrm{A}$ & $112(40.0)$ & $135(48.9)$ & $A$ & 0.39 & 0.43 & \\
\hline & $\mathrm{A} / \mathrm{A}$ & $53(18.9)$ & $51(18.5)$ & & & & \\
\hline \multirow[t]{3}{*}{ rs9939609 T>A } & $\mathrm{T} / \mathrm{T}$ & $115(41.1)$ & $90(32.6)$ & $\mathrm{T}$ & 0.61 & 0.57 & 0.9002 \\
\hline & $\mathrm{T} / \mathrm{A}$ & $112(40.0)$ & $135(48.9)$ & A & 0.39 & 0.43 & \\
\hline & $\mathrm{A} / \mathrm{A}$ & $53(18.9)$ & $51(18.5)$ & & & & \\
\hline \multicolumn{8}{|l|}{$P P A R \gamma$} \\
\hline \multirow[t]{2}{*}{ rs $10865710 \mathrm{C}>\mathrm{G}$} & $\mathrm{C} / \mathrm{C}$ & $183(65.4)$ & $169(61.2)$ & C & 0.83 & 0.81 & $<0.001$ \\
\hline & $\mathrm{C} / \mathrm{G}$ & $97(34.6)$ & $107(38.8)$ & G & 0.17 & 0.19 & \\
\hline \multirow[t]{2}{*}{ rs $17036263 A>G$} & $\mathrm{~A} / \mathrm{A}$ & $273(97.5)$ & $269(97.5)$ & $A$ & 0.99 & 0.99 & 1.00 \\
\hline & $\mathrm{A} / \mathrm{G}$ & $7(2.5)$ & $7(2.5)$ & G & 0.01 & 0.01 & \\
\hline \multirow[t]{2}{*}{ rs $1801282 \mathrm{C}>\mathrm{G}$} & $\mathrm{C} / \mathrm{C}$ & $237(84.6)$ & $242(87.7)$ & C & 0.92 & 0.94 & 0.6095 \\
\hline & $\mathrm{C} / \mathrm{G}$ & $43(15.4)$ & $34(12.3)$ & G & 0.08 & 0.06 & \\
\hline \multirow[t]{2}{*}{ rs $41516544 \mathrm{~A}>\mathrm{G}$} & $\mathrm{A} / \mathrm{A}$ & $243(86.8)$ & $273(98.9)$ & A & 0.93 & 0.99 & 1.00 \\
\hline & $\mathrm{A} / \mathrm{G}$ & $37(13.2)$ & $3(1.1)$ & G & 0.07 & 0.01 & \\
\hline \multirow[t]{2}{*}{ rs3856806 C > T } & $\mathrm{C} / \mathrm{C}$ & $199(71.1)$ & $225(81.5)$ & C & 0.86 & 0.91 & 0.1458 \\
\hline & $\mathrm{C} / \mathrm{T}$ & $81(28.9)$ & $51(18.5)$ & $\mathrm{T}$ & 0.14 & 0.09 & \\
\hline
\end{tabular}

HWE: hardy Weinberg equilibrium. P-values for each allele and each group are shown.

\section{Discussion}

It is generally accepted that the cause for IUGR development is the combination of maternal, placental, fetal, and genetic factors $(5,6)$. In the current study, we conducted an HRM analysis together with DNA sequencing in a Brazilian population from a Ribeirão Preto birth cohort to address genetic risk factors and maternal factors, which may be associated with IUGR.

Our finding of a highly significant association of $P P A R \gamma$ rs41516544 on IUGR is the most interesting result in this paper. Other studies have investigated the association between PPAR $\gamma$ rs41516544 and type 2 diabetes with increased risk of metabolic complications such as T2DM, insulin resistance, and obesity $(18,30)$. Thus, finding an SNP that is related to both IUGR and adult metabolic diseases is particularly interesting in light of the association between IUGR and diabetes in adults observed in British populations by Barker et al. (1).

Other SNPs in PPAR $\gamma$ have been studied in the context of T2M, in particular rs1801282 (31). The observed size and nature of the association between T2M and rs1801282 are not yet clearly established. In an Indian population, the association is positive but statistically insignificant in nonobese subjects (31). In the same paper, a meta-analysis was carried out using results from many different studies and different ethnic groups. In some of these studies, the OR is significantly larger than 1 , and in others, significantly less than 1. Many studies found no evidence for any effect (31). None of the studies cited in that meta-analysis were from populations in Latin America. Furthermore, Morgan et al. (13) found no association between rs1801282 and SGA. In light of these studies on rs1801282 and known associations between IUGR and T2DM, and T2DM with rs41516544, our findings relating rs41516544 with an increased risk for IUGR independent of the sex of the offspring are relevant.

We also investigated potential confounders and environmental factors that might contribute to this association such as maternal smoking, age, and education. Earlier studies have shown that maternal smoking is associated with a reduction in birth weight (32) and this 
Table 3. Distribution and unadjusted association of genotype and other maternal characteristics with intrauterine growth restriction (IUGR).

\begin{tabular}{|c|c|c|c|c|c|}
\hline \multirow[t]{2}{*}{ Variables* } & \multicolumn{2}{|c|}{ IUGR $(n, \%)$} & \multirow[t]{2}{*}{ OR } & \multirow[t]{2}{*}{$95 \% \mathrm{Cl}$} & \multirow[t]{2}{*}{$P$-value } \\
\hline & Yes & No & & & \\
\hline \multicolumn{6}{|c|}{ FTO rs9939609 } \\
\hline Male & $n=124$ & $n=129$ & & & 0.059 \\
\hline $\mathrm{T} / \mathrm{T}$ & $54(43.5)$ & $36(27.9)$ & 1.00 & & \\
\hline$T / A$ & $47(37.1)$ & $69(53.5)$ & 0.50 & $0.29-0.79$ & \\
\hline $\mathrm{A} / \mathrm{A}$ & $23(18.5)$ & $24(18.6)$ & 0.72 & $0.35-1.49$ & \\
\hline Female & $n=156$ & $n=147$ & & & 0.929 \\
\hline $\mathrm{T} / \mathrm{T}$ & $61(39.1)$ & $54(36.7)$ & 1.00 & & \\
\hline T/A & $65(41.7)$ & $66(44.9)$ & 0.91 & $0.55-1.52$ & \\
\hline $\mathrm{A} / \mathrm{A}$ & $30(19.2)$ & $27(18.4)$ & 1.00 & $0.53-1.92$ & \\
\hline \multicolumn{6}{|c|}{ PPAR rs 41516544} \\
\hline Male & $\mathrm{n}=124$ & $\mathrm{n}=129$ & & & $<0.001$ \\
\hline $\mathrm{A} / \mathrm{A}$ & $101(81.5)$ & $128(99.2)$ & 1.00 & & \\
\hline $\mathrm{A} / \mathrm{G}$ & $23(18.5)$ & $1(0.8)$ & 28.29 & $3.73-214.51$ & \\
\hline Female & $\mathrm{n}=156$ & $n=147$ & & & 0.011 \\
\hline $\mathrm{A} / \mathrm{A}$ & $142(91.0)$ & $145(98.6)$ & 1.00 & & \\
\hline$A / G$ & $14(9.0)$ & $2(1.4)$ & 7.10 & $1.58-31.98$ & \\
\hline \multicolumn{6}{|c|}{ Maternal age (years) } \\
\hline Male & & & & & 0.543 \\
\hline $20-34$ & $97(78.2)$ & $99(76.7)$ & 1.00 & & \\
\hline$\geqslant 35$ & $11(8.9)$ & $16(12.4)$ & 0.68 & $0.30-1.55$ & \\
\hline$<20$ & $16(12.9)$ & $14(10.9)$ & 1.22 & $0.55-2.68$ & \\
\hline Female & & & & & 0.019 \\
\hline $20-34$ & $124(80.0)$ & $114(77.6)$ & 1.00 & & \\
\hline$\geqslant 35$ & $8(5.2)$ & $19(12.9)$ & 0.33 & $0.13-0.82$ & \\
\hline$<20$ & $23(14.8)$ & $14(9.5)$ & 1.60 & $0.77-3.31$ & \\
\hline \multicolumn{6}{|c|}{ Maternal schooling (years) } \\
\hline Male & & & & & 0.123 \\
\hline$<9$ & $96(78.7)$ & $86(68.8)$ & 1.00 & & \\
\hline$\geqslant 9$ & $26(21.3)$ & $39(31.2)$ & 0.64 & $0.36-1.13$ & \\
\hline Female & & & & & 0.685 \\
\hline$<9$ & $120(77.9)$ & $113(79.6)$ & 1.00 & & \\
\hline$\geqslant 9$ & $34(22.1)$ & 29 (20.4) & 1.12 & $0.64-1.97$ & \\
\hline \multicolumn{6}{|c|}{ Maternal smoking } \\
\hline Male & & & & & 0.027 \\
\hline No & $75(61.0)$ & $94(75.2)$ & 1.00 & & \\
\hline Yes & $48(39.0)$ & $31(24.8)$ & 1.86 & $1.07-3.21$ & \\
\hline Female & & & & & 0.003 \\
\hline No & $94(61.0)$ & $109(76.8)$ & 1.00 & & \\
\hline Yes & $60(39.0)$ & $33(23.2)$ & 2.15 & $1.29-3.58$ & \\
\hline
\end{tabular}

*Variation in number and percentage in some categories of the variables is due to missing information. 'P-value for chi-squared test. FTO: fat mass and obesity-associated; PPAR $\gamma$ : peroxisome proliferatoractivated receptor-gamma.

association has been observed in numerous different populations $(33,34)$. In our analysis, we found that maternal smoking increased the risk for IUGR only for female offspring $(\mathrm{OR}=1.93,95 \% \mathrm{Cl}$ : 1.14-3.28), suggesting a manifestation of gender differences on the effects of cigarette smoking. In fact, Lockhart et al. observed a significant increase of serotonin in smoking mothers carrying male fetuses compared with smoking mothers carrying female fetuses (35). However, factors associated with the intrauterine environment, which lead to these differences, require further research.

This is the first study to report data on the prevalence of alleles of FTO and PPAR genes associated with IUGR in Brazil. However, we were unable to include maternal variables that are related to the intrauterine growth of the offspring, such as maternal pre-pregnancy weight and 
Table 4. Adjusted associations of FTO (fat mass and obesity-associated) and $P P A R \gamma$ (peroxisome proliferator-activated receptor-gamma) genotypes and maternal characteristics with intrauterine growth restriction (IUGR).

\begin{tabular}{|c|c|c|c|c|}
\hline & \multicolumn{2}{|c|}{ Male } & \multicolumn{2}{|c|}{ Female } \\
\hline & OR & $95 \% \mathrm{Cl}$ & OR & $95 \% \mathrm{Cl}$ \\
\hline \multicolumn{5}{|c|}{ FTO rs9939609 } \\
\hline TT & 1.00 & & 1.00 & \\
\hline TA & 0.47 & $0.26-0.86$ & 1.02 & $0.60-1.74$ \\
\hline AA & 0.74 & $0.34-1.62$ & 1.02 & $0.51-2.07$ \\
\hline \multicolumn{5}{|c|}{ PPAR $\mathrm{rs} 41516544$} \\
\hline AA & 1.00 & & 1.00 & \\
\hline AG & 27.83 & 3.65-212.32 & 8.94 & $1.96-40.88$ \\
\hline \multicolumn{5}{|c|}{ Maternal age (years) } \\
\hline $20-34$ & 1.00 & & 1.00 & \\
\hline$\geqslant 35$ & 0.61 & $0.24-1.56$ & 0.29 & $0.11-0.83$ \\
\hline$<20$ & 1.22 & $0.52-2.88$ & 1.45 & $0.67-3.12$ \\
\hline \multicolumn{5}{|c|}{ Maternal schooling (years) } \\
\hline$<9$ & 1.00 & & 1.00 & \\
\hline$\geqslant 9$ & 0.66 & $0.36-1.24$ & 1.31 & $0.72-2.37$ \\
\hline \multicolumn{5}{|c|}{ Maternal smoking } \\
\hline No & 1.00 & & 1.00 & \\
\hline Yes & 1.47 & $0.81-2.69$ & 1.93 & $1.14-3.28$ \\
\hline
\end{tabular}

Adjusted for maternal age, schooling, and smoking during pregnancy.

weight gain during gestation (36), as they were not available in the original birth cohort. Nonetheless, the environmental factors and potential confounders included do appear to play a role in IUGR.

Maternal age appears to be associated with a reduced risk for IUGR female offspring only and for mothers above the age of 35 only $(\mathrm{OR}=0.29,95 \% \mathrm{Cl}: 0.11-0.83)$, also suggesting a gender-specific response whose mechanism remains unknown. The association between maternal age and risk for IUGR from other studies is ambiguous. A population-based study from a Northeastern Brazilian city, where IUGR rates of $16.2 \%$ are observed, has shown no significant association between maternal age and increased prevalence of IUGR (37). However, in another meta-analysis including 63 cohort studies and 12 casecontrol studies, higher maternal age increases the risk of fetal growth restriction (38). Furthermore, the design of most studies does not consider male and female offspring separately as we did in the current study, and therefore the mechanisms of these maternal age effects require further research that must consider both genders separately and include genetic, epigenetic, demographic, and socioeconomic factors.

In our study, we also demonstrated that FTO rs9939609 TA genotype was associated with a reduced risk for IUGR in male offspring only $(\mathrm{OR}=0.47,95 \% \mathrm{Cl}: 0.26-0.86)$. The FTO rs9939609 variant is a well-studied SNP that has been associated with higher BMI, risk of obesity, and subsequent T2DM development $(15,16,20)$. A meta-analyses conducted by Peng et al. (21) demonstrated the correlation between FTO rs9939609 and obesity, which was observed in 21 of the 29 studies. These data have shown that the association of FTO rs9939609 and risk for obesity might depend on ethnicity. Furthermore, the studies analyzed in Peng et. al. (21) included only one South American population from Mexico. Hence, additional studies in different ethnic groups are important to get a clearer picture of the effects of rr993609. Our data show that the FTO rs9939609 TA genotype has a protective effect against IUGR, but only in male offspring with no effect in female offspring, suggesting that gender-specific factors may underlie these differences. Although the understanding of the full details of the relationship between FTO with IUGR is not complete, the results shown here are of interest.

In conclusion, we found a gender-specific association of the FTO rs9939609 TA genotype with IUGR, showing a reduced risk among male offspring. On the other hand, the PPARy rs41516544 AG genotype showed a highly significant risk of IUGR in both sexes. These associations were found even after controlling for non-genetic confounding factors. These results are interesting, but should be validated in a larger study in an independent birth cohort.

\section{Acknowledgments}

K.J. Abraham was supported at the beginning of this investigation by the International Visiting Professor Program at University of São Paulo (Process number: 13.1.1318.17.3). This study was supported by São Paulo 
Research Foundation (FAPESP, grant 2000/09508-7), Foundation for the Support for Education, Research and Assistance of Hospital das Clínicas of the Ribeirão Preto Medical School of the University of São Paulo (FAEPA), and the National Research Council (CNPq, Edital Universal grant 480604/2013-4). This study was financed in part by the Coordenação de Aperfeiçoamento de Pessoal de Nível Superior-Brasil (CAPES, Finance Code 001).

\section{References}

1. Barker DJ, Gluckman PD, Godfrey KM, Harding JE, Owens JA, Robinson JS. Fetal nutrition and cardiovascular disease in adult life. Lancet 1993; 341: 938-941, doi: 10.1016/01406736(93)91224-A.

2. Vayssiere $C$, Sentilhes L, Ego A, Bernard C, Cambourieu D, Flamant $C$, et al. Fetal growth restriction and intra-uterine growth restriction: guidelines for clinical practice from the French College of Gynaecologists and Obstetricians. Eur $J$ Obstet Gynecol Reprod Biol 2015; 193: 10-18, doi: 10.1016/ j.ejogrb.2015.06.021.

3. Korzeniewski SJ, Allred EN, Joseph RM, Heeren T, Kuban KCK, O'Shea TM, et al. Neurodevelopment at age 10 years of children born $<28$ weeks with fetal growth restriction. Pediatrics 2017; 140: e20170697, doi: 10.1542/peds.20170697.

4. Sehgal A, Skilton MR, Crispi F. Human fetal growth restriction: a cardiovascular journey through to adolescence. J Dev Orig Health Dis 2016; 7: 626-635, doi: 10.1017/ S2040174416000337.

5. Sharma D, Shastri S, Sharma P. Intrauterine growth restriction: antenatal and postnatal aspects. Clin Med Insights Pediatr 2016; 10: 67-83, 10.4137/CMPed.S40070.

6. Fleiss B, Wong F, Brownfoot F, Shearer IK, Baud O, Walker $D W$, et al. Knowledge gaps and emerging research areas in intrauterine growth restriction-associated brain injury. Front Endocrinol (Lausanne) 2019; 10: 188, 10.3389/fendo.2019. 00188.

7. Isganaitis E. Developmental programming of body composition: update on evidence and mechanisms. Curr Diab Rep 2019; 19: 60, doi: 10.1007/s11892-019-1170-1.

8. Hattersley AT, Tooke JE. The fetal insulin hypothesis: an alternative explanation of the association of low birthweight with diabetes and vascular disease. Lancet 1999; 353: 1789-1792, doi: 10.1016/S0140-6736(98)07546-1.

9. Klebanoff MA, Schulsinger C, Mednick BR, Secher NJ. Preterm and small-for-gestational-age birth across generations. Am J Obstet Gynecol 1997; 176: 521-526, doi: 10.1016/S0002-9378(97)70540-4.

10. Ghezzi F, Tibiletti MG, Raio L, Di Naro E, Lischetti B, Taborelli M, Franchi M. Idiopathic fetal intrauterine growth restriction: a possible inheritance pattern. Prenat Diagn 2003; 23: 259-264, doi: 10.1002/pd.571.

11. Aguayo-Armendariz J, Montalvo-Corral M, Gonzalez-Martinez KA, Grijalva-Haro MI, Ballesteros-Vasquez MN, CaireJuvera $G$, et al. Central obesity and body fat, but not body mass index, are associated with the Pro12Ala polymorphism in the peroxisome proliferator-activated receptor gamma gene in a population with a high consumption of saturated and trans-fatty acids. Nutr Res 2018; 57: 28-35, doi: 10.1016/j.nutres.2018.05.003.

12. Butt H, Shabana, Hasnain S. The C1431T polymorphism of peroxisome proliferator activated receptor gamma (PPARgamma) is associated with low risk of diabetes in a Pakistani cohort. Diabetol Metab Syndr 2016; 8: 67, doi: 10.1186/ s13098-016-0183-z.

13. Morgan AR, Thompson JM, Murphy R, Black PN, Lam WJ, Ferguson LR, et al. Obesity and diabetes genes are associated with being born small for gestational age: results from the Auckland Birthweight Collaborative study. BMC Med Genet 2010; 11: 125, doi: 10.1186/1471-2350-11-125.

14. Frayling TM, Timpson NJ, Weedon MN, Zeggini E, Freathy $\mathrm{RM}$, Lindgren CM, et al. A common variant in the FTO gene is associated with body mass index and predisposes to childhood and adult obesity. Science 2007; 316: 889-894, doi: 10.1126/science.1141634.

15. Younus LA, Algenabi AHA, Abdul-Zhara MS, Hussein MK. FTO gene polymorphisms (rs9939609 and rs17817449) as predictors of Type 2 Diabetes Mellitus in obese Iraqi population. Gene 2017; 627: 79-84, doi: 10.1016/j.gene. 2017.06.005.

16. Montesanto A, Bonfigli AR, Crocco $P$, Garagnani $P$, De Luca $\mathrm{M}$, Boemi M, et al. Genes associated with Type 2 Diabetes and vascular complications. Aging (Albany NY) 2018; 10: 178-196, doi: 10.18632/aging.101375.

17. Dong C, Zhou H, Shen C, Yu LG, Ding Y, Zhang YH, et al. Role of peroxisome proliferator-activated receptors gene polymorphisms in type 2 diabetes and metabolic syndrome. World J Diabetes 2015; 6: 654-661, doi: 10.4239/wjd.v6. i4.654.

18. Karambataki M, Malousi A, Kouidou S. Risk-associated coding synonymous SNPs in type 2 diabetes and neurodegenerative diseases: genetic silence and the underrated association with splicing regulation and epigenetics. Mutat Res 2014; 770: 85-93, doi: 10.1016/j.mrfmmm.2014.09.005.

19. Zeggini E, Scott LJ, Saxena R, Voight BF, Marchini JL, Hu T, et al. Meta-analysis of genome-wide association data and large-scale replication identifies additional susceptibility loci for type 2 diabetes. Nat Genet 2008; 40: 638-645, doi: 10.1038/ng. 120 .

20. Blond MB, Schnurr TM, Rosenkilde M, Quist JS, Gram AS, Reichkendler $\mathrm{MH}$, et al. PPARG Pro12Ala Ala carriers exhibit greater improvements in peripheral insulin sensitivity in response to 12 weeks of aerobic exercise training. Physiol Genomics 2019; 51: 254-260, doi: 10.1152/physiolgenomics. 00101.2018

21. Peng $\mathrm{S}$, Zhu $\mathrm{Y}, \mathrm{Xu} F$, Ren $\mathrm{X}$, Li X, Lai M. FTO gene polymorphisms and obesity risk: a meta-analysis. BMC Med 2011; 9: 71.

22. Marsh JA, Pennell CE, Warrington NM, Mook-Kanamori D, Briollais L, Lye SJ, et al. Fat mass and obesity-associated obesity-risk genotype is associated with lower foetal growth: an effect that is reversed in the offspring of smoking mothers. J Dev Orig Health Dis 2012; 3: 10-20, doi: 10.1017/S20401 74411000638.

23. Barbieri MA, Bettiol H, Silva AA, Cardoso VC, Simoes VM, Gutierrez MR, et al. Health in early adulthood: the 
contribution of the 1978/79 Ribeirao Preto birth cohort. Braz J Med Biol Res 2006; 39: 1041-1055, doi: 10.1590/ S0100-879X2006000800007.

24. Rodie VA, Young A, Jordan F, Sattar N, Greer IA, Freeman DJ. Human placental peroxisome proliferator-activated receptor delta and gamma expression in healthy pregnancy and in preeclampsia and intrauterine growth restriction. J Soc Gynecol Investig 2005; 12: 320-329, doi: 10.1016/ j.jsgi.2005.03.004.

25. Diaz M, Bassols J, Lopez-Bermejo A, Gomez-Roig MD, de Zegher F, Ibanez L. Placental expression of peroxisome proliferator-activated receptor gamma $(P P A R \gamma)$ : relation to placental and fetal growth. J Clin Endocrinol Metab 2012; 97: E1468-E1472, doi: 10.1210/jc.2012-1064.

26. Leeuwerke M, Eilander MS, Pruis MG, Lendvai A, Erwich JJ, Scherjon SA, et al. DNA methylation and expression patterns of selected genes in first-trimester placental tissue from pregnancies with small-for-gestational-age infants at birth. Biol Reprod 2016; 94: 37, doi: 10.1095/biolreprod. 115.131698 .

27. Kramer MS, Platt $R$, Yang $H$, McNamara $H$, Usher RH. Are all growth-restricted newborns created equal(ly)? Pediatrics 1999; 103: 599-602, doi: 10.1542/peds.103.3.599.

28. Radulescu L, Ferechide D, Popa F. The importance of fetal gender in intrauterine growth restriction. J Med Life 2013; 6: 38-39.

29. Anderson CA. Data quality control in analysis of complex disease association studies - a pratical guide. Zeggini E, Morris A (Editors); Cambridge: Academic Press; 2011. p 95108.

30. Handschin C, Spiegelman BM. Peroxisome proliferatoractivated receptor gamma coactivator 1 coactivators, energy homeostasis, and metabolism. Endocr Rev 2006; 27: 728735, doi: 10.1210/er.2006-0037.

31. Phani NM, Vohra M, Rajesh S, Adhikari P, Nagri SK, D'Souza SC, et al. Implications of critical PPARgamma2,
ADIPOQ and FTO gene polymorphisms in type 2 diabetes and obesity-mediated susceptibility to type 2 diabetes in an Indian population. Mol Genet Genomics 2016; 29: 193-204, doi: 10.1007/s00438-015-1097-4.

32. Simpson WJ. A preliminary report on cigarette smoking and the incidence of prematurity. Am J Obstet Gynecol 1957; 73: 807-815, doi: 10.1016/0002-9378(57)90391-5

33. Pereira PP, Da Mata FA, Figueiredo AC, de Andrade KR, Pereira MG. Maternal active smoking during pregnancy and low birth weight in the Americas: a systematic review and meta-analysis. Nicotine Tob Res 2017; 19: 497-505, doi: 10.1093/ntr/ntw228.

34. Kobayashi S, Sata F, Hanaoka T, Braimoh TS, Ito K, Tamura $\mathrm{N}$, et al. Association between maternal passive smoking and increased risk of delivering small-for-gestational-age infants at full-term using plasma cotinine levels from The Hokkaido Study: a prospective birth cohort. BMJ Open 2019; 9: e023200, doi: 10.1136/bmjopen-2018-023200.

35. Lockhart F, Liu A, Champion BL, Peek MJ, Nanan RKH, Poulton AS. The effect of cigarette smoking during pregnancy on endocrine pancreatic function and fetal growth: a pilot study. Front Public Health 2017; 5: 314, doi: 10.3389/ fpubh.2017.00314.

36. Goldstein RF, Abell SK, Ranasinha S, Misso M, Boyle JA, Black $\mathrm{MH}$, et al. Association of gestational weight gain with maternal and infant outcomes: a systematic review and meta-analysis. JAMA 2017; 317: 2207-2225, doi: 10.1001/ jama.2017.3635.

37. Figueiredo ED, Lamy Filho F, Lamy ZC, Silva AA. Maternal age and adverse perinatal outcomes in a birth cohort (BRISA) from a Northeastern Brazilian city. Rev Bras Ginecol Obstet 2014; 36: 562-568, doi: 10.1590/so100-720320140005161.

38. Lean SC, Derricott H, Jones RL, Heazell AEP. Advanced maternal age and adverse pregnancy outcomes: a systematic review and meta-analysis. PLoS One 2017; 12: e0186287, doi: 10.1371/journal.pone.0186287. 